\section{PCR Cloning: New Parameters for Managing Alzheimer's Dementia}

Alzheimer's disease (AD) is a chronic neuro-degenerative disorder that usually starts after the age of 65 years and progresses slowly, worsening recall memory in individuals. With further advancement of the disease, impairments in language, disorientation, mood swings with ultimate loss of body functions and death ensue. The cause, of the disease is considered to be genetic in $70 \%$ of the cases, while other possible risk factors include chronic stressed conditions such as depression, anxiety, and even hypertension. ${ }^{1} \mathrm{AD}$ progression is associated with formation of tau entangles and amyloid plaques in the brain, a main reason of worsening behavioural and physical deterioration in Alzheimer patients. Examination of brain tissue is always required for definite diagnosis. Since it cannot be done in the live subjects, it will be imperative to find any gene/protein that can become a potential marker for AD; and may be detected in brain for the potential diagnosis and treatment of this disorder. ${ }^{2}$

One of such genes/proteins is a histone binding protein, RbAp48 (RBBP4), a major genetic risk factor for Alzheimer's dementia. ${ }^{3}$ Its deficiency occurs at the dentate-gyrus of hippocampus in brain. Its main functions are to facilitate ATP-dependent chromatin remodelling along with histone deacetylase activity through interaction with $\mathrm{H} 3-\mathrm{H} 4$ dimers combinedly coined as nucleosome remodelling deacetylase complex; and to act as co-repressor in transcription silencing, regulating cell proliferation, growth and post- translational modification of the nucleosome. Any disturbance in its structure or function may interrupt neuronal activity disrupting memory encoding ability. 4

Cloning is a technique where recombinant DNA can be integrated into host organism for generation of required genes and eventually desired proteins for the preferred results. Three Kb pGEMT is the replicon with augmented T7 and SP6 RNA polymerase having multiple cloning sites and other essential features that include recognition of insertion of gene through BstZl, EcoRI and Notl as well as manifestation of ampicillin resistant gene as selective marker for vector growth in ampicillin supplemented media. ${ }^{5}$ PCR product of RbAp48 gene can be incorporated in pGEMT for cloning purpose and transformed into competent cells to achieve the magnitude of product. Recombinant clones can be directly evaluated

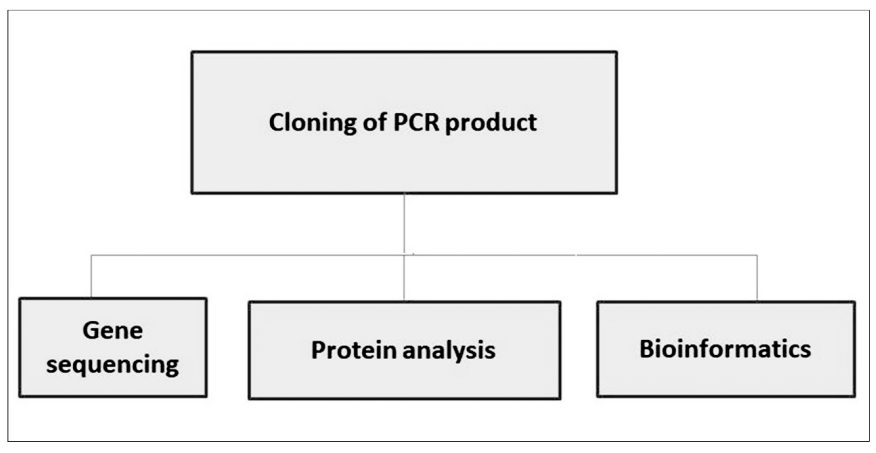

Figure 1: Different methods for the analysis of PCR cloned products.

through blue/white selection of colony, restriction digestion, and electrophoresis of pGEMT generated PCR copies of the gene. Restriction digestion is done using restriction endonuclease to separate our gene of interest from replicon and then perform Sanger sequencing for mutational analysis (Figure 1). This will assist in identification of the alteration in the protein sequence involved in memory loss in AD.

\section{REFERENCES}

1. Denk J, Oberhauser F, Kornhuber J, Wiltfang J, Fassbender K, Schroeter ML, et al. Specific serum and CSF microRNA profiles distinguish sporadic behavioural variant of frontotemporal dementia compared with Alzheimer patients and cognitively healthy controls. PLoS One 2018; 13: e0197329

2. Lu JX, Qiang W, Yau WM, Schwieters CD, Meredith SC, Tycko R. Molecular structure of beta-amyloid fibrils in Alzheimer's disease brain tissue. Cell 2013; 154:1257-68.

3. Huang HJ, Lee CC, Chen CY. Lead discovery for Alzheimer's disease related target protein $\mathrm{RbAp} 48$ from traditional Chinese medicine. Biomed Res Int 2014; 2014:764946.

4. Pavlopoulos E, Jones S, Kosmidis S, Close M, Kim C, Kovalerchik $\mathrm{O}$, et al. Molecular mechanism for age-related memory loss: The histone-binding protein RbAp48. Sci Transl Med 2013; 5:200ra115.

5. Litterer L. Comparing cloning efficiency of the $\mathrm{pGEM}^{{ }_{-}-\mathrm{T}}$ and pGEM $^{\circledR}-T$ easy vectors to the TOPO TA cloning ${ }^{\circledR}$ vectors. Scientific style and format, $7^{\text {th }}$ edition, 2006.

Asra Khan, Rehana Rehman and Saara Ahmad

Biological and Biomedical Sciences, The Aga Khan University Hospital, Karachi, Pakistan

Correspondence: Dr. Saara Ahmad, Biological and

Biomedical Sciences, The Aga Khan University Hospital,

Karachi, Pakistan

E-mail: saara.muddasir@aku.edu

Received: May 18, 2018; Accepted: December 04, 2018

$$
\text { …두.... }
$$

